\title{
THE FAILURE OF AIR CONDITIONING SYSTEM IN B737NG AIRCRAFT
}

\author{
Anindia Istikomah \\ Prodi Teknik Penerbangan, Prodi Teknik Penerbangan, Prodi Teknik Penerbangan \\ Sekolah Tinggi Teknologi Adisutjipto \\ Jalan Janti Blok R Lanud Adisutjipto Yogyakarta \\ aninhernanda@gmail.com
}

\begin{abstract}
The analysis done by the FMEA and RCFA methods shows that the main cause of the damage because of the accumulation of impurities. And it often occurs in the Heat Exchanger (Hx) component. In Indonesia with the special condition where the air has a relatively higher humidity and air temperature, it is recommended to clean the heat exchanger more frequently to prevent dirt build up and avoid the problem of AC in producing hot air on the ground. In the standard maintenance manual the heat exchanger must be cleaned with 2000 FC (Flight Cycle) intervals, then the heat exchanger cleaning interval is changed to around 1000 FC (Flight Cycle) based on calculations performed by GMF.
\end{abstract}

Keyword: FMEA, $A C$ and $G M F$

\section{Latar Belakang}

Air conditioning (AC) adalah salah satu sistem untuk mendukung kenyamanan dan keamanan penumpang pesawat terbang. AC pesawat berfungsi sebagai pengendali tekanan dan suhu ruangan di dalam pesawat. Mengingat pentingnya peran AC maka maintenance yang dilakukan juga harus diperhatikan dengan baik. Sistem AC pesawat terang dibagi atas 4 bagian yaitu distribution, cooling system, temperature control, dan pressuritation [3]. Di bagian temperature control terdapat komponen tambahan yang disebut control panel. Control panel yang berada di cockpit pilot berfungsi sebagai pengendali dan monitoring proses air conditioning didalam pesawat. Apabila terjadi kerusakan pada salah satu bagian system AC maka pilot akan bisa memonitor langsung sehingga pilot bisa mengetahui dan mencatat kerusakan yang terjadi pada bagian-bagian yang ada pada air conditioning [1][2]. Kerusakan yang bisa terjadi pada AC pesawat digolongankan menjadi kerusakan ringan dan berat yang menyebabkan suhu di dalam kabin pesawat lebih tinggi daripada suhu standart. Kerusakan ringan misalnya adalah kerusakan pada cabin temperature sensor filter yang menyebabkan udara tidak tersaring dengan baik, sehingga temperature sensor tidak dapat mendeteksi temperature yang sebenarnya. Kerusakan seperti ini bisa diatasi dalam waktu singkat dengan mengganti atau membersihkan filter tersebut. Kerusakan yang dianggap berat adalah kerusakan yang membutuhkan waktu lama untuk memperbaikinya dan hanya dilakukan saat pesawat melakukan maintenance rutin di GMF-Aeroasia [5].

\section{Metodologi Penelitian}

Beberapa metode Penelitian, antara lain:

a. Pengamatan data dan identifikasi masalah

Langkah awal penelitian ini adalah pengamatan tentang data kerusakan khususnya pada AC pesawat yang diberikan PT. GMF-Aeroasia. Data tersebut dari bulan januari 2017 hingga juli 2018 dengan tiga permasalahan yang diberikan. Proses pengamatan data dilakukan dengan pengelompokan masalah yang terdapat didata lalu di tampilkan dalam 
bentuk grafik. Grafik tersebut digunakan sebagai identifiasi masalah yang lebih baik sering terjadi dari data problem pada AC pesawat terbang. Kemudian didapatkan hasil bahwa prolem air conditioning produces hot air adalah problem yang harus ditangani [5][7].

b. Studi Pustaka

Merupakan suatu motede pengumpulan data berdasarkan pada study kepustakaan yang digunakan sebagai pedoman dalam penulisan laporan dari bidang yang diambil, dalam hal ini data dapat diperoleh berdasarkan bukti-bukti kejadian serta menganalisanya kembali.

c. Personal interview

Merupakan suatu metode pengumpulan data dengan cara menanyakan langsung pada mekanik, engineer, atau pembimbing lapangan.

Agar penelitian ini dapat menghasilkan hasil yang sesuai, maka pengolahan data yang dilakukan adalah sebagai berikut :

a. Pengelompokan Data

Memilih dan mengelompokan data yang diperoleh agar dapat diproses dan diinterprestasikan.

b. $\quad$ Reporting System

Menampilkan grafik dari hasil analisis data yang diperoleh merupakan laporan yang berisi data-data dan rangkuman aktivitas yang sudah pernah dilakukan.

c. Evaluation and Analysis

Merupakan langkah untuk mengevaluasi kegagalan ataupun kerusakan pada air conditionong system pada pesawat Boeing 737NG. Dalam evaluasi disini penulis menggunakan analisis Failure Mode and Effect Analysis (FMEA)yang kemudian di dukung dengan hasil analisis dari honeywell sebagai manufaktur dengan Root Cause Failure Analysis (RCFA)[4].

Dengan adanya permasalahan pada $A C$ produces hot air pada pesawat Boeing $737 \mathrm{NG}$ berdasarkan pilot report (PIREP), maka diperlukan suatu analisis untuk mengevaluasi dengan menganilisis kegagalan maupun kerusakan yang ada berdasarkan dengan data yang tersedia. Metode analisis data merupakan metode penyususan data agar mampu diterjemahkan, mengerjakan data, menatanya, membaginya menjadi satu kesatuan yang dapat dikelola, mencari pola, menemukan apa yang perlu dilaporkan. Metode analisis yang digunakan adalah dengan menggunakan metode analisis reliability seperti metode FMEA dan metode RCFA yang digunakan untuk mengidentifikasi permasalahan kegagalan dan kerusakan dari suatu komponen pada bagian AC. Dimana metode RCFA dibuat untuk menguatkan hasil analisis dari metode FMEA.

\subsection{Prinsip Kerja Sistem}

Diagram kerja dari sistem rerigeresi pada pesawat terbang secara umum dapat dilihat pada gambar 1 . 


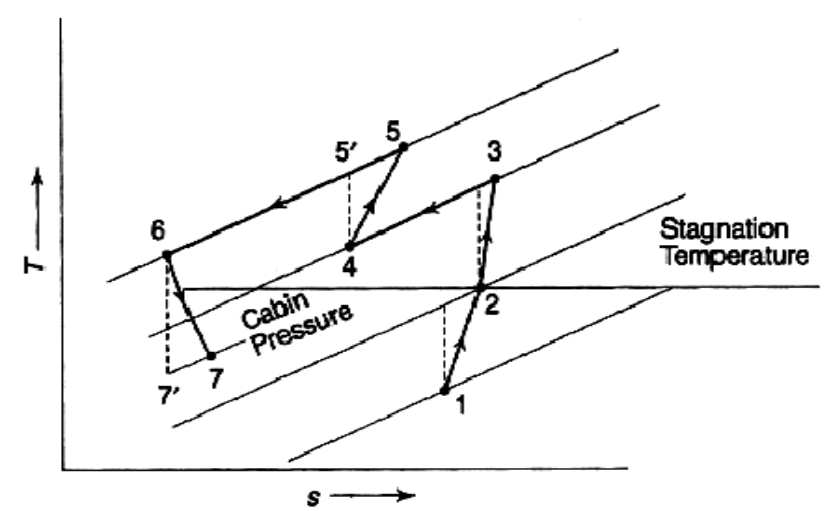

Gambar 1. Diagram T-S untuk Sistem Bootstrap

Proses yang terjadi :

1-2: Proses stagnasi udara

Proses ini terjadi ketika udara dari luar (ambient air temperature) mengalir masuk dalam disfuser compresor jet engine, pada proses ini terjadi kenaikan tekanan dan suhu udara akibat perlambatan kecepatan.

2-3 : Proses kompresi udara

Di sini udara dikompresikan, idealnya proses ini terjadi pada entropi konstan (isentropi) tetapi tekanan, suhu dan entalpi naik. Proses ini dilakukan oleh kompresor mesin pesawat dan sejumlah 6-7\% udara terkompresi dialirkan ke sistem pengkondisian udara.

3-4 : Proses pendinginan pada primary heat exchanger

Udara terkompresi mengalami penurunan temperature pada tekanan konstan karena mengalami pertukaran panas dengan udara luar .

4-5 : Proses kompresi pada kompresor ACM (Air Cycle Machine).

Udara mengalami proses kompresi sehingga menimbulkan kenaikan tekanan dan suhu, proses ini dilakukan oleh kompresor pada ACM.

5-6 : Proses pendinginan pada secondary heat exchanger

Pada proses ini udara terkompresi mengalami proses penurunan suhu lagi pada tekanan konstan atau terjadi pada proses isobar.

6-7 : Proses ekspansi pada turbin

Pada proses ini terjadi ekspansi udara oleh turbin sehingga udara mengalami penurunan tekanan dan suhu. Suhu dan tekanan yang didapatkan biasanya melebihi standart sehingga dilakukan mixing sebelum udara dapat didistribusikan menuju kabin.

Air Cycle Machine (ACM) adalah unit refrigerasi yang digunakan dalam pesawat, umumnya pesawat mempunyai 2-3 unit yang tersusun yang disebut "pack". ACM terdiri dari satu kompresor, 2 heat exchanger dan sebuah turbin ekspansi. Fungsi turbin adalah untuk mengekspansikan udara bertekanan sehingga menurunkan temperaturnya. Turbin dan kompresor tersebut terletak pada posisi di dalam satu poros maksudnya adalah apabila kompressor bekerja maka turbin juga ikut bekerja yang dikarenakan oleh satu poros tersebut.

Secara rinci kerja ACM adalah sebagai berikut. Dimulai dari udara yang keluar pada turbo jet fan compressor memiliki temperature dan tekanan yang tinggi. Kemudian udara yang bertekanan dan bertemperature tinggi tersebut disalurkan ke dalam heat exchanger (Primary heat exchanger). Proses didalam heat exchanger, udara yang keluar 
dari heat exchanger yang sudah terkondisikan tersebut masuk ke dalam compressor. Didalam compressor tersebut terjadi perubahan tekanan dan temperatur dan tekanan. Udara keluaran dari compressor tersebut menghasilkan kenaikan pada temperatur dan tekanan. Udara terkondisi yang berada pada saluran keluar compressor tersebut, kemudian disalurkan kembali ke dalam heat exchanger (secondary heat exchanger). Didalam heat exchanger tersebut terjadi penurunan temperatur dan tekanan yang sebelumnya udara mengalami kenaikan di temperatur dan tekanan pada posisi keluar compressor. Dari heat exchanger, udara masuk ke turbin, di sini udara mengalami ekspansi sehingga tekanan dan temperaturnya turun. Setelah dari turbin udara mempunyai kelembapan tinggi, oleh karena itu udara disalurkan ke water separator (pemisah cairan). Didalam alat ini terjadi pemisahan uap air yang dari udara sehingga udara mengalami penurunan suhu, selain itu terjadi pembersihan udara dengan menyaring kotoran. Bentuk alat ini menyerupai kerucut yang didalamnya terdepat semacam saringan (filter). Inilah akhir dari proses pendinginan yang selanjutnya didistribusikan ke kabin penumpang. Sistem ac pesawat harus bisa bekerja baik saat pesawat ada didarat atau diudara. Uraian berikut menjalaskan perbedaan saat AC pesawat bekerja di darat (on the ground) dan di udara (in flight).

\section{Hasil dan Pembahasan}

Analisa permasalahan yang terdapat pada data di GMF Aeroasia. Analisa data pertama yang diberikan adalah data Flight Hours. Data Flight Hours dihitung dari rata-rata waktu pesawat itu bekerja tiap bulannya. Selain dari data Flight Hours, diberikan juga data perawatan pesawat di GMF Aeroasia tiap bulannya. Data perawatan tersebut kemudian diklasifikasikan dari tiap-tiap problemnya. Langkah pengklasifikasian bertujuan agar memundahkan mendapatkan problem tiap bulannya. Kedua data dianalisi dengan menghitung problem di data perawatan tiap bulannya $\times 1000 \div$ flight hours total. Hasil dari perhitungan tersebut terletak pada tabel 1 Hasil tersebut analisi tersebut digunakan untuk mendapatkan grafik PILOT REPORT RATE tiap bulannya. Grafik Pilot Report (PIREP) Rate tersebut bisa di lihat pada gambar 2.

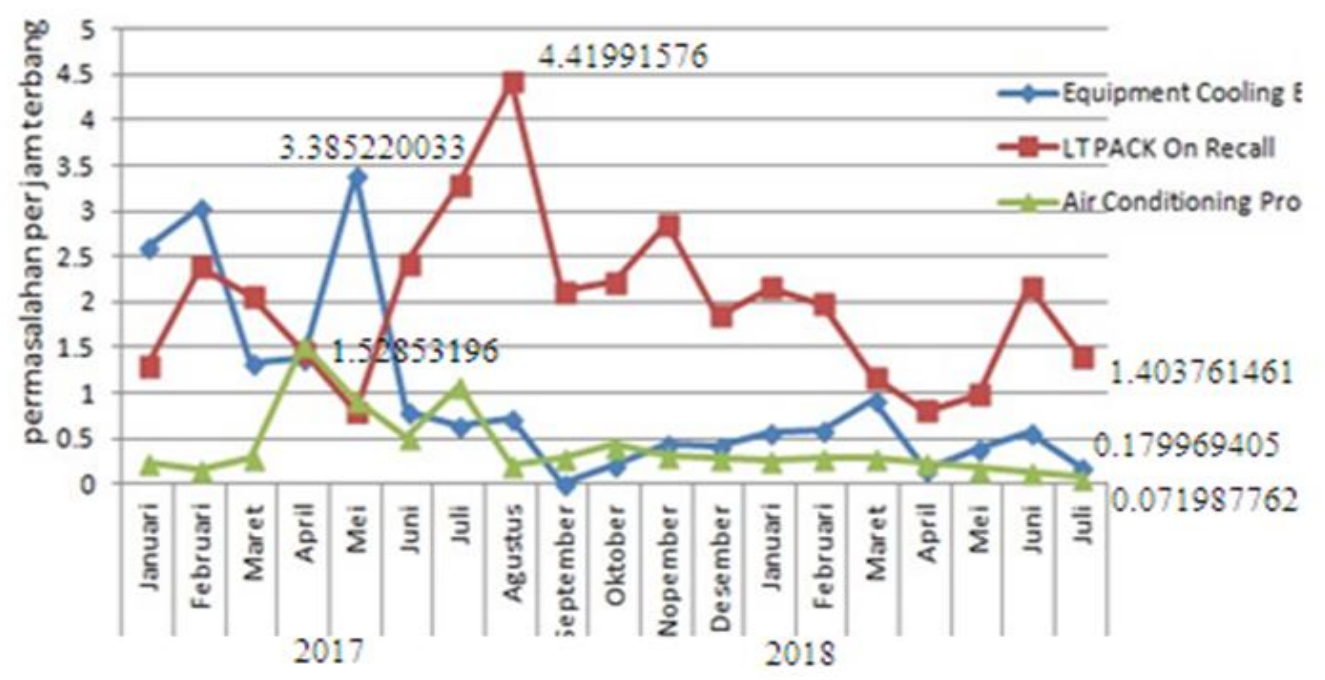

Gambar 2. Pilot Report Rate 
Pada masalah equipment cooling dibulan mei 2017 menunjukkan hasil yaitu 3,38522033. Angka tersebut menunjukkan angka paling besar untuk problem equipment cooling, yang dapat diartikan bahwa problem equipment cooling dibulan mei 2017 lebih banyak dibandingkan flight hours-nya. Pada bulan juli 2018, masalah equipment cooling menunjukkan angka 0,179969305. Hal ini menunjukkan masalah sudah tertangani dengan baik di GMF Aeroasia karena mengalami penurunan.

Problem LT Pack On Recall pada gambar grafik PIREP RATE tersebut menunjukan hasil yang sangat besar yaitu 4.41991576. kemudian mengalami penurunan yang sangat drastis hingga bulan april 2018, data problem LT Pack On Recall pada grafik pirep rate ini menunjukkan angka 1,40376136 dibulan april 2018. Rasio naik turunnya problem ini berdasarkan gambar 4.1 adalah 3.0. Hal ini menunjukkan bahwa masalah LT Pack On Recall sudah bisa dianggap terselesaikan karena menunjukkan tren 4,41991576 menjadi 1,40376136.

Untuk gambar tren pada masalah air conditioning produces hot air menunjukkan angka 1,5285319 produces pada bulan april 2017. Dan menunjukkan angka 0,071987762. Pada gambar grafik tersebut didapatkan hasil bahwa permasalahan air conditioning produces hot air on ground masih menunjukkan tren grafik yang masih stagnan. Hal ini menunjukkan permasalahan yang didapat di GMF masih belum dapat teratasi. Berbeda dengan tren grafik yang ditunjukkan pada permasalahan Equipment Cooling Exhaust dan LT Pack On Recall yang telah menunjukan tren grafik yang cukup menurun/tidak stagnan. Hal tersebut juga dapat dibandingkan pada perbandingan rasio turunnya grafik pada masing-masing masalah. Masalah air conditioning produces hot air memang tidak menunjukan angka paling tinggi pada gambar grafik tersebut, akan tetapi perbandingan rasionya perubahan tiap bulan pada problem air conditioning produce hot air adalah yang paling kecil atau ditunjukan pada gambar grafik menunjukkan tidak adanya perubahan garis grafik (stagnan). Maka dari itu problem air conditioning produces hot air tersebut disimpulkan masih belum terselesaikan di GMF Aeroasia.

Heat Exchanger mempunyai equipment berfungsi sebagai media pendingin yaitu cooling air plenum/diffuser. Di dalam RCFA heat exchanger dijelaskan kegagalan di dalam heat exchanger dan cooling air plenum/diffuser. Di dalam heat exchanger terjadi kegagalan karena tersumbatnya saluran heat exchanger dikarenakan adanya kotoran atau zat tercemar yang masuk ke dalam inlet heat exchanger tersebut. Hal tersebut yang menyebabkan ACM atau menyebabkan suhu di dalam cabin tidak dingin yang dikarenakan oleh kontaminasi yang berasal dari heat exchanger.karena berdasarkan sistem AC pesawat terbang, proses pertama kali terjadi pendinginan adalah dibagian heat exchanger/primary heat exchanger.

Cooling plenum/diffuser terjadi 3 jenis kegagalan yaitu patahnya mount brakets, tersumbatnya saluran, dan juga rusaknya pada door stop. Untuk kegagalan yang terjadi pada patahnya mount brackets penyebabnya adalah meningkatnya tegangan getaran dan suhu. Untuk kegagalan selanjutnya adalah kegagalan kegagalan pada tersumbatnya saluran equipment pendingin (cooling air plenum/diffuser) dikarenakan adanya zat tercemar atau kotoran yang masuk ke media pendingin tersebut.hal tersebut juga yang menyeabkan terjadinya AC pesawat tidak dingin karena media pendingin heat exchanger tersumbat oleh kotoran. Kegagalan selanjutnya adalah kegagalan pada rusaknya door stop pada plenum diffuser. Rusaknya door stop ini dikarenakan terkenanya impact secara terus menerus di door stop sehingga menyebabkan terjadinya kerusakan.

Berdasarkan dari hasil RCFA (Root Cause Failure Analysis) yang telah dilakukan,hasil menunjukkan bahwa akar permasalahan dari kegagalan equipment $\mathrm{AC}$ pesawat adalah terkontaminasi atau kotor. Kotoran tersebut dapat masuk kedalam sistem AC pesawat terbang melalui udara luar yang dapat mengurangi kerja pendingin $\mathrm{AC}$ pesawat terbang.kotoran tersebut masuk pertama kali melewati engine compressor lalu ke heat exchanger (primary) 
yang akan diteruskan ke dalam kompressor ACM (Air Cycle Machine) kemudian masuk secondary heat excahnger dan selanjutnya masuk ke turbin ACM. Pembersihan kedua heat exchanger secara lebih sering akan menghindari kerusakan ACM karena penumpukkan kotoran. Jika dalam standart maintenance manual harus dibersihkan heat exchanger dengan interval $2000 \mathrm{FC}$ (Flight Cycle) maka dirubah interval pembersihan heat exchanger menjadi sekitar $100 \mathrm{FC}$ (Flight Cycle) berdasarkan perhitungan yang dilakukan oleh pihak GMF.

\section{Kesimpulan}

Berdasarkan dari hasil RCFA (Root Cause Failure Analysis) yang telah dilakukan,hasil menunjukkan bahwa akar permasalahan dari kegagalan equipment AC pesawat adalah terkontaminasi atau kotor. Kotoran tersebut dapat masuk kedalam sistem AC pesawat terbang melalui udara luar yang dapat mengurangi kerja pendingin AC pesawat terbang.kotoran tersebut masuk pertama kali melewati engine compressor lalu ke heat exchanger (primary) yang akan diteruskan ke dalam kompressor ACM (Air Cycle Machine) kemudian masuk secondary heat excahnger dan selanjutnya masuk ke turbin ACM. Pembersihan kedua heat exchanger secara lebih sering akan menghindari kerusakan ACM karena penumpukkan kotoran. Jika dalam standart maintenance manual harus dibersihkan heat exchanger dengan interval $2000 \mathrm{FC}$ (Flight Cycle) maka dirubah interval pembersihan heat exchanger menjadi sekitar $1000 \mathrm{FC}$ (Flight Cycle) berdasarkan perhitungan yang dilakukan oleh pihak GMF

\section{Daftar Pustaka}

[1] Boeing, 2018, Aircraft Maintenance Manual 737NG Chapter 21, Boeing, United State.

[2] Ilham Aulia, 2014, Analisis penyebab kegagalan air conditioning system Boeing 737-900 ER

[3] Hendra, 2009, Analisis keandalan komponen air conditioning system pada pesawat Boeing 737-900 Er mengunakan metode distribusi weibull

[4] Stamatis, D.H. 1995. Failure Mode And Effect Analysis : FMEA from Theory to Execution Milwaukee : ASQC QualityPress

[5] SAEJ-1739, Failure Mode and Effect Analysis, AIAG \& ASQC, USA

[6] Boeing 737NG Specification Copyright (C) 2008-2018 www.airlines-inform.com All right reserved (diakses 29 agustus 2019) 